\title{
GOVERNANÇA CORPORATIVA: PERCEPÇÃO DAS EMPRESAS QUANTO ÀS PRÁTICAS DE GOVERNANÇA CORPORATIVA E A ENTRADA NO NOVO MERCADO DA BOVESPA ${ }^{1}$
}

\author{
SANTOS, Carolina M. dos ${ }^{2}$ \\ SILVA, Julio César Celestino ${ }^{3}$ \\ SILVA, Rodrigo Augusto Celestino ${ }^{4}$
}

\begin{abstract}
RESUMO: O ganho de eficiência na gestão aliado ao aumento da liquidez do Mercado de Capitais Brasileiro e à sua importância no financiamento das empresas resultam na maior transparência das informações divulgadas pelas empresas. Atualmente, a expressiva quantidade de empresas que utilizam práticas de Governança Corporativa sugere que tais métodos resulta em benefícios para as companhias que as adotam. A maior valorização das ações das empresas que compõem o IGC (Índice de Governança Corporativa) e ganhos com maior visibilidade, menores custos de capital e melhora da profissionalização na gestão sugerem que as empresas obtêm vantagens ao ingressar no Novo Mercado nível máximo de Governança Corporativa no mercado brasileiro. A Governança Corporativa e suas práticas contribuem para o aumento da confiabilidade dos investidores, colaboradores, instituições financeiras e mercado em geral. Sabendo-se da importância das práticas de Governança Corporativa, o objetivo do presente trabalho foi identificar a percepção das empresas no Novo Mercado da Bovespa, abordando os impactos da Governança Corporativa, tendo como principal foco as empresas listadas no Novo Mercado da Bovespa. Para tanto, elaborou-se um questionário com perguntas especificas sobre os benefícios e obstáculos enfrentados pela Governança e a entrada e manutenção no novo segmento de listagem da Bovespa, o Novo Mercado. Verificou-se que as empresas, ao adotarem práticas de Governança Corporativa, possuem expectativa de valorização e aumento de liquidez das ações, o que, de fato, ocorre após a implantação dessas práticas. Nota-se ainda que existem entraves quanto à implantação e manutenção da Governança como a conscientização de colaboradores, tempo e excesso de exigências legais para atuação nos seguimentos diferenciados de listagem. A entrada no Novo Mercado da BOVESPA possui vantagens quanto à valorização das ações, o crescimento do interesse de investidores estrangeiros e a visibilidade da companhia no mercado. Seus entraves estão relacionados à dificuldade de conceder igualdade de condições a minoritários e possuir todas ações em negociação, sendo ordinárias. Ressalta-se que formar um Conselho de Administração e Conselho Fiscal, em muitos casos independentes, torna-se um obstáculo enfrentado pelas empresas.
\end{abstract}

Palavras-chave: Governança corporativa. Mercado de capitais. Novo mercado.

SUMMARY: The profit of efficiency in the management ally to the increase of the liquidity of the Brazilian Stock Market and to its importance in the financing of the companies' results in the biggest transparency of the information divulged by the companies. Nowadays, the expressive amount of companies that use practical of Corporative Governance suggests that such methods result in benefits for the company that adopt them. The biggest valuation of the actions of the companies that compose the IGC (Index of Corporative Governance) and profits with bigger visibility, minor capital costs and improve of professionalization in the management, suggest that the companies get advantages when entering the New Market maximum level of Corporative Governance in the Brazilian market. Practical of Corporative Governance contribute to the increase of the trustworthiness of the investors, collaborators, financial institutions and market in general. Knowing the importance of practical 1 Apresentado como Trabalho de Conclusão de Curso à Faculdade de Filosofia Ciências e Letras, Fundação Educacional de Ituverava para obtenção do título de Bacharel em Administração.

2 Bacharel em Administração - Agronegócios.

3 Bacharel em Administração - Gestão de Negócios.

4 Orientadora: MSc. em Administração das Organizações. Prof. ${ }^{a}$ da Faculdade de Filosofia Ciências e Letras, Fundação Educacional de Ituverava. carol_1708@yahoo.com.br 
of Corporative Governance, the objective of the present work was to identify the perception of the companies in the New Market of the São Paulo Stock Exchange, approaching the impacts of the Corporative Governance, having as main focus the companies listed in the New Market of BOVESPA. In such a way, a questionnaire with questions was elaborated with specified questions about benefits and obstacles faced by Governance and the entrance and maintenance in new segment of listing of BOVESPA, the New Market. It was verified that the companies when adopting Corporative Governance possess expectation of valuation and increase of liquidity of the actions, that, in fact, occurs after implantation of these practical. It is also noticed that impediments exist in relation to the implantation and maintenance of the Governance, as awareness of collaborators, time and excess of legal requirements for performance in the differentiated pursuings of listing. The entrance in the New Market of BOVESPA has advantages to valuation of the actions, the growth of the interest of foreign investors and the visibility of the company in the market. Its impediments are related to the difficulty of granting equality of conditions to minorities and to possess all actions in negotiation, being usual. It is standed out that to form an Advice of Administration and Statutory Audit Committee, in many independent cases, an becomes obstacle faced for the companies.

Keywords: Corporate Governance. Capital market. New market.

\section{INTRODUÇÃO}

O fortalecimento da economia brasileira com a redução da dívida externa, aumento do volume de dólares em reservas cambiais, superávit dabalança comercialaliado àprofissionalização e internacionalização das empresas brasileiras fez o risco-país ${ }^{5}$ cair a patamares abaixo da média de países emergentes e gerou muita confiança em investidores espalhados pelo mundo, fazendo a BOVESPA bater recordes consecutivos.

O Mercado de Capitais no Brasil tem se apresentado cada vez mais como uma importante fonte de financiamento de capital para as empresas e como uma rentável forma de aplicação de recursos financeiros para investidores nacionais e estrangeiros.

Nos últimos três anos, a Bolsa de Valores de São Paulo tem batido consecutivos recordes. As aberturas de capital na BOVESPA tiveram um aumento significativo; em 2005, apenas 9 empresas abriram seu capital. Em 2006, foram 26 lançamentos de ações e, até o inicio do segundo semestre de 2007, abriram capital mais 47 empresas, acumulando um crescimento de $89 \%$ (BOVESPA, 2007).

O elevado volume financeiro, também, pode ser observado pela análise dos principais investidores. Em 2007, o volume de negociação de investidores estrangeiros representa mais de $35 \%$ das negociações, os investidores institucionais possuem $27 \%$; as pessoas físicas, com $20 \%$; instituições financeiras, com $12 \%$; as empresas, com $5 \%$ e outros investidores, com $0,12 \%$ do volume total negociado. Observa-se que, principalmente, o volume de pessoas físicas tem aumentado substancialmente, sendo que, há dez anos, esse percentual de investidores não passava de 10\%. Além disso, o volume de empresas que abrem capital no Mercado de Ações também cresce. No final de Julho de 2007, a BOVESPA contabilizou 388 empresas listadas

5 Diferença entre a taxa interna de retorno do Brasil e a taxa de juros do bônus do Tesouro norte-americano de mesmo prazo. (BOVESPA, 2007) 
com valor de mercado de R\$2,1 Trilhões (BOVESPA, 2007).

O principal interesse das empresas no mercado de ações está na captação de recursos financeiros de longo prazo, já que os juros cobrados no país são dos mais altos do mundo e a única fonte com recursos mais baratos é o Banco Nacional de Desenvolvimento Econômico e Social (BNDES) que possui recursos limitados (BARBOSA, 2006).

As empresas já utilizam mais o mercado de capitais do que o $\mathrm{s}$ empréstimos no BNDES para obtenção de recursos. Em 2006, o volume de empréstimos do BNDES foi de $\mathrm{R} \$ 52$ bilhões enquanto que o volume captado na BOVESPA foi de $\mathrm{R} \$ 110$ bilhões. Tal fato aumenta a importância do Mercado de Capitais no fornecimento de recursos a longo prazo para as empresas. (CARVALHO; PAUL; NAIDITCH, 2007)

Tamanho crescimento do Mercado de Capitais resulta na necessidade de transparência nas informações prestadas ao mercado em geral. Em resposta a esse cenário, surge, principalmente idealizada pela BOVESPA, a Governança Corporativa.

Segundo o Instituto Brasileiro de Governança Corporativa (IBGC), “A Governança Corporativa é o sistema que assegura aos sócios/proprietários o governo estratégico da empresa e a efetiva monitoração da diretoria executiva. A relação entre propriedade e gestão se dá através do conselho de administração, auditoria independente e o conselho fiscal. A boa Governança fornece aos acionistas, equidade, transparência e alinhamentos às leis do país". (IBGC, 2007)

Aimportância da Governança Corporativa está refletida na maior participação de empresas que lançam suas ações no Novo Mercado, nível máximo de Governança Corporativa. Dessa forma, o objetivo do presente artigo foi identificar a percepção das empresas no Novo Mercado da Bovespa, abordando os impactos da Governança Corporativa, tendo, como principal foco, as empresas listadas no Novo Mercado da Bovespa. Para tanto, elaborou-se um questionário com perguntas especificas sobre os benefícios e obstáculos enfrentados pela Governança e a entrada e manutenção no novo segmento de listagem da Bovespa, o Novo Mercado. Para a realização da pesquisa, foram aplicados questionários enviados através de e-mails às empresas que possuem ações listadas no Novo Mercado. Por meio do seu departamento de Relações com Investidores, identificaram-se os motivos pelos quais as empresas abrem seu capital e adotam práticas de Governança Corporativa. Verificaram-se, assim, as razões da implantação da Governança Corporativa em um número crescente de empresas, abordando os impactos positivos e as dificuldades enfrentadas pelas companhias para manutenção dessas práticas. Além disso, abordou-se a percepção das empresas listadas no Novo Mercado da BOVESPA quanto aos benefícios e entraves desse segmento.

\section{REFERENCIAL TEÓRICO}




\subsection{MERCADO DE CAPITAIS}

O Mercado de Capitais Brasileiro iniciou-se no final do século passado, com a abertura da chamada Bolsa livre, onde eram negociados títulos públicos e ações de bancos e empresas. Porém o amadurecimento desse mercado ocorreu na década de 60, após as reformas sofridas no mercado financeiro nacional e a formação de corretoras que constituíram, a parir desta data, a Bolsa de Valores de São Paulo - BOVESPA, uma entidade institucional, civil e sem fins lucrativos. Também, nessa época, surge o operador de pregão que negociava os títulos através de gritos e gestos. (BOVESPA, 2007)

Ainda segundo a BOVESPA (2007), no fim da década de 1990, foi lançado o Home Broker, que permite que o investidor, por meio de site das Corretoras, transmita sua ordem de compra ou de venda diretamente ao sistema de negociação da bolsa, e o After-Market, que oferece a sessão noturna de negociação eletrônica. Ambos os meios facilitam a participação dos pequenos e médios investidores no mercado financeiro e contribuem para o aumento da liquidez do mercado de capitais.

A partir do ano 2000, começa um movimento de integração das demais bolsas brasileiras com a BOVESPA, que, em 2006, tornou-se a única bolsa de valores dos país e a de maior importância na América Latina, concentrando cerca de 70\% das negociações realizadas nesta região. (BOVESPA, 2007)

ABovespa investiu em Tecnologia da Informação para aumentar o volume de negociações e garantir maior segurança e velocidade das informações para os investidores. Hoje, todas as transações são realizadas através de meios eletrônicos, dispensando a necessidade dos operadores de pregão, que eram figuras marcantes da bolsa de valores.

Para fiscalizar e disciplinar o mercado de valores mobiliários, foi criada a Comissão de Valores Mobiliários (CVM), instituída através da Lei 6.385/76. A CVM possui como competências criar meios para estimular a formação de poupança e sua aplicação em valores mobiliários, promover a expansão e eficiência, estimulando aplicações em ações do capital social das companhias abertas, evitar e coibir fraudes ou manipulação e proteger os titulares de valores mobiliários. Em síntese, a principal atribuição da CVM é gerar segurança às companhias e acionistas do Mercado de Capitais. (CVM, 2007)

Com todas essas mudanças ocorridas na BOVESPA, o mercado de capitais tem se tornado um grande financiador das empresas brasileiras. Sabe-se que, por diversos motivos, as empresas abrem seu capital na Bolsa de Valores, e um dos principais é a necessidade de adquirir recursos financeiros de longo prazo para fomentar o crescimento. Além da captação de recursos, especialistas identificam outros motivos para abertura de capital como necessidade de arranjo societário, desenvolvimento da imagem institucional ou fuga dos fundos de private equity ${ }^{6}$.

A abertura de capital é feita por meio da oferta pública de ações, ou seja, primeiro lançamento de ações ao público realizado por uma empresa ou operações de underwriting. "O 6 Modalidade de fundo de investimento que compra participação acionária em empresas. Direcionado para negócios que já funcionam e têm, em geral, boa geração de caixa. (BOVESPA, 2007) 
underwriting é um esquema de lançamento de emissão de ações para subscrição pública, no qual a empresa encarrega um intermediário financeiro da colocação desses títulos no mercado". Antes desse lançamento, a empresa é normalmente uma sociedade limitada, cujas negociações com valores mobiliários são privadas e não atingidas pelas leis e normativos que regem as operações em bolsa. (CVM, 2007)

Conforme Pinheiro (2001), “as ações são títulos de participação negociáveis que representam parte do capital social de uma sociedade econômica, que confere ao seu possuidor o direito de participação nos resultados da mesma. Podem ser consideradas como certificado ou título de propriedade, representativo das partes do capital social de uma sociedade econômica. O acionista é, portanto, proprietário de uma parcela da empresa, correspondente ao numero de ações que possui".

Existem dois tipos de ações. Ação ordinária é a que outorga direito a voto, concedendo ao acionista o direito de participação na administração da sociedade e nos resultados financeiros. A ação preferencial, por sua vez, não concede o direito ao voto, porém confere direito preferencial nos resultados da empresa. (PINHEIRO, 2001)

Segundo Barbosa (2006), a ação ordinária, sigla ON, concede direito de votar nas assembléias de acionistas. Embora não tenha poder de veto, a possibilidade de voto é muito importante, se houver divergência de interesse entre os acionistas controladores e os minoritários. A ação preferencial, sigla PN, não dá direito a voto, mas quem a adquire recebe, primeiro, a sua parte do lucro da empresa, ou seja, possui preferência no recebimento de dividendos. Por outro lado, em caso de venda da companhia, nem todas as organizações garantem o prêmio pago pelo comprador para ficar com o controle da empresa para esse tipo de ação.

Alguns números desse mercado efervescente demonstram um crescimento surpreendente. Segundo Salomão; Salgado; Caetano (2007), o valor de mercado das companhias de capital aberto no Brasil atingiu níveis recordes, multiplicando-se sete vezes. O número médio de negócios, por dia, é 14 vezes maior em relação ao ano de 1995, o número de investidores pessoa física triplicou em sete anos, de 76,5 mil para 245 mil pessoas. Esse aumento no número de acionista pessoa física foi auxiliado pela implantação de clubes de investimentos na BOVESPA que são organizados pelas corretoras por grupos de interesses similares como advogados, professores, aposentados etc. Esses clubes aumentaram cerca de 340\% desde o ano 2000, e percebe-se um crescente interesse do cidadão brasileiro por esse tipo de investimento.

Esse cenário positivo tem contribuído para o aumento da importância do Mercado de Capitais como principal fonte de financiamento das empresas brasileiras. As empresas, porém, possuem uma necessidade crescente de profissionalizar sua gestão com maior transparência, a fim de receberem capital de novos acionistas. Nesse cenário, percebe-se a necessidade de utilizar práticas de gestão em benefício da empresa e de seus sócios/investidores, ou seja, a Governança Corporativa. 


\subsection{GOVERNANÇA CORPORATIVA}

Com a necessidade de tornar o mercado de ações organizado e mais seguro para os acionistas e a urgência na profissionalização das empresas médias, ao longo dos anos, as entidades envolvidas nesses processos criaram métodos para essa transformação e, atualmente, as empresas listadas na Bolsa de Valores são relacionadas de forma distinta no que se refere à gestão. Surge um novo termo no mercado financeiro brasileiro, a Governança Corporativa.

A BOVESPA define Governança Corporativa como "Sistema pelo qual as sociedades são dirigidas e monitoradas, envolvendo os relacionamentos entre Acionistas/Cotistas, Conselho de Administração, Diretoria, Auditoria Independente e Conselho Fiscal”. A Governança Corporativa adota uma tríade como linha mestra de práticas que são: a prestação de contas, a transparência e a equidade.

Segundo o Instituto Brasileiro de Governança Corporativa (IBGC) (2007), "Os conselheiros profissionais e independentes começaram a surgir, basicamente, em resposta à necessidade de atrair capital e fontes de financiamento para a atividade empresarial, o que foi acelerado pelo processo de globalização e pelas privatizações de empresas estatais no país".

Foram criados pela Bovespa níveis diferenciados de governança corporativa, em que as empresas se classificam pela disposição em se tornarem-se mais transparentes e oferecerem mais garantias para os investidores, que são preceitos básicos da Governança, e diferenciam-se por implantarem regras além das exigidas pela legislação.

Conforme demonstrado por Cicogna; Toneto; Valle (2007), a adesão a essas novas práticas de governança distingue a companhia como pertencente ao Nível 1, Nível 2 ou Novo Mercado, dependendo do grau de compromisso assumido pela empresa. A empresa será classificada como Nível 1, se assumir um comprometimento com melhorias na qualidade das informações dadas ao mercado e com pulverização acionária. A Nível 2, além das obrigações contidas no Nível1, a companhia adota um conjunto mais amplo de práticas de governança como o aumento do número de conselheiros, sendo $20 \%$ desses profissionais independentes. Além disso, é necessária a adoção da Câmara de Arbitragem do Mercado para resolução de conflitos acionários. As informações de demonstrações financeiras devem obedecer ao padrão internacional, e devem ser estabelecidos direitos adicionais para os acionistas minoritários.

No Novo Mercado, a principal melhoria é o dever de possuir $100 \%$ das ações ordinárias em sua estrutura de capital e ampliar, em nível máximo, o direito dos acionistas minoritários. Constituem-se, então, quatro segmentos diferentes para classificação das ações na Bovespa, Mercado Tradicional, Novo Mercado, Nível 1 e Nível2. Atualmente as companhias estão listadas nas seguintes quantidades: Mercado Tradicional - 295 empresas, Nível 1 - 40 empresas, Nível 2 - 18 empresas, Novo Mercado - 80 empresas, totalizando 433 empresas listadas. (BOVESPA, 2007)

Sabe-se que existem alguns índices no mercado de capitais para guiarem os investidores como IBOVESPA, IBRX 50, IGC e ISE. Conforme esclarece a BOVESPA, o IBOVESPA 
(Índice Bovespa) “é uma carteira teórica composta pelas ações que, em conjunto, representam $80 \%$ do volume transacionado à vista, nos doze meses anteriores à formação da carteira. Como critério adicional, exige-se que a ação apresente, no mínimo, $80 \%$ de presença nos pregões do período". O IBRX 50 (Índice Brasil 50) "é uma carteira composta por 50 ações selecionadas entre as mais negociadas da BOVESPA, em termos de liquidez, ponderadas na carteira pelo valor de mercado das ações disponíveis à negociação". O IGC (Índice de Ações com Governança Corporativa Diferenciada) sugere "uma carteira composta por ações de companhias listadas nos segmentos especiais da BOVESPA”. Tais segmentos são os já destacados Nível 1, Nível 2 e Novo Mercado. O índice mais recente de todos surgiu no final de 2005, em resposta à tendência de valorização das empresas sustentáveis, o ISE (Índice de Sustentabilidade Empresarial) que possui sua carteira formada por companhias analisadas em quatro dimensões: econômicofinanceira, social, ambiental e governança corporativa. Esses índices servem de parâmetro para aplicações do investidor, e um grande percentual do mercado orienta-se por eles. (BARBOSA, 2006)

Nos últimos seis anos, o índice que apresenta a maior evolução é o IGC, superando o IBRX50 e o IBOVESPA. O interesse dos investidores nas empresas que possuem práticas diferenciadas de governança corporativa dá-se através da observação de que essas possuem maior valorização de suas ações e, conseqüentemente, maior rentabilidade conforme demonstra o gráfico abaixo:

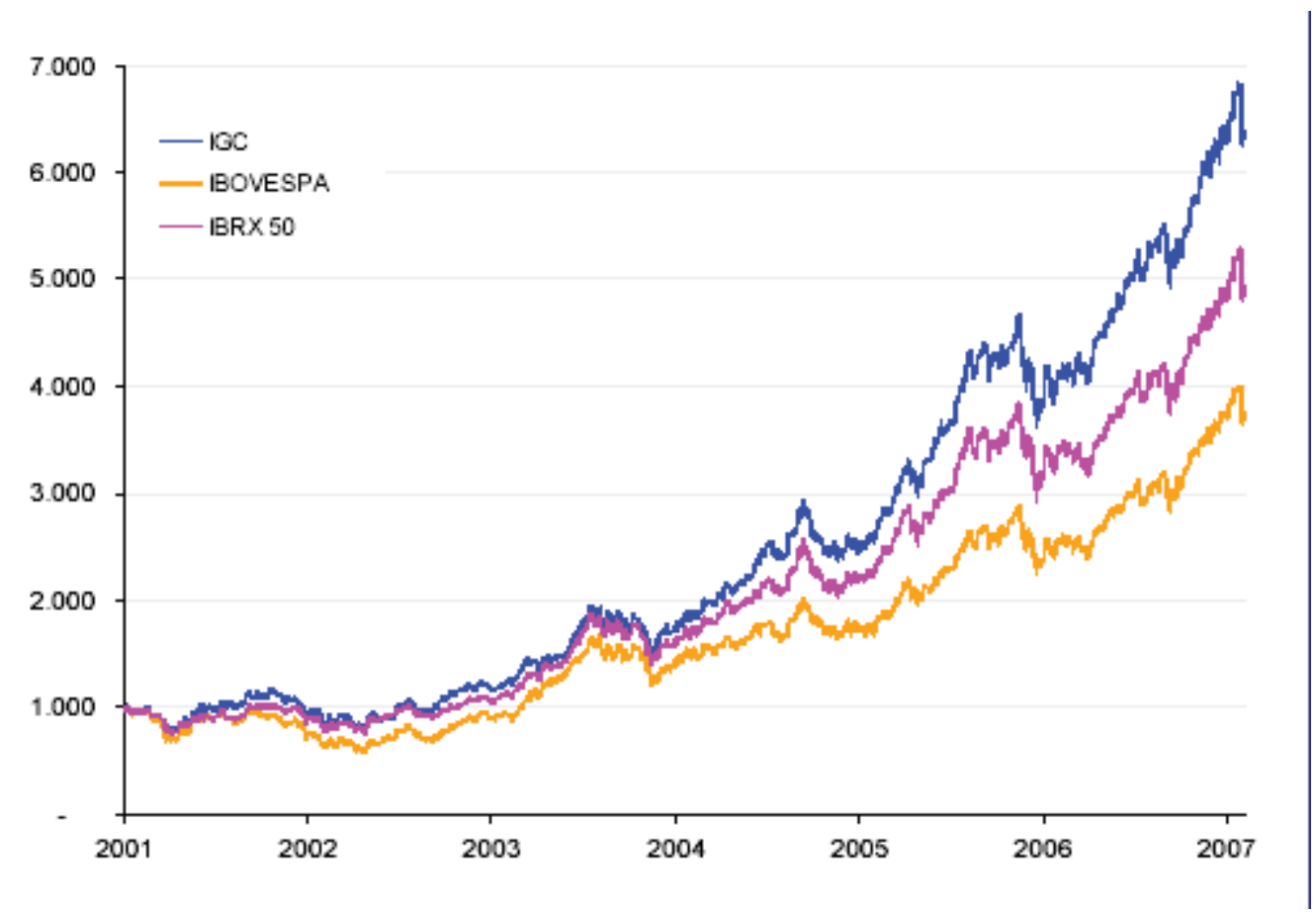

Gráfico 1: Evolução do IBOVESPA x IBRX 50 x IGC (base 1.000 = 25/06/2001) Fonte: BOVESPA (2007)

Percebe-se que o Novo Mercado é o principal seguimento na Bovespa, por obter o maior número de práticas diferenciadas de governança corporativa e por conter, entre os níveis 
de Governança Corporativa, o maior número de empresas listadas atualmente. Essas empresas estão divididas nos seguintes seguimentos:

Tabela 1: Número de empresas listadas no Novo Mercado por setor

\begin{tabular}{c|c|c}
\hline Segmento & Quantidade de empresas & Participação (\%) \\
\hline Petróleo e Gás & 1 & $1,25 \%$ \\
\hline Materiais Básicos & 3 & $3,75 \%$ \\
\hline Bens Industriais & 7 & $8,75 \%$ \\
\hline Construção e Transporte & 25 & $31,25 \%$ \\
\hline Consumo Não Cíclico & 17 & $21,25 \%$ \\
\hline Consumo Cíclico & 6 & $7,5 \%$ \\
\hline Tecnologia da Informação & 4 & $5 \%$ \\
\hline Telecomunicações & 1 & $1,25 \%$ \\
\hline Utilidade Pública & 6 & $7,5 \%$ \\
\hline Financeiro e Outros & 10 & $12,5 \%$ \\
\hline TOTAL & $\mathbf{8 0}$ & $\mathbf{1 0 0 \%}$
\end{tabular}

Fonte: BOVESPA (2007).

Os principais benefícios percebidos pelas empresas, ao entrarem no Novo Mercado, é o crescimento do interesse de capital estrangeiro e de grandes investidores individuais nas ações da empresa. A melhoria nos processos de gestão da empresa é uma conseqüência das práticas de Governança Corporativa adotadas anteriormente à entrada nesse segmento especial de listagem da Bolsa de Valores de São Paulo, mas que representa fator importante para a companhia. Além disso, a empresa entende que outro benefício alcançado é a redução do custo de capital por meio do lançamento de ações e também pela aquisição de empréstimos em instituições financeiras que, através do aumento de informações disponíveis sobre a empresa, reduzem o risco do empréstimo do capital e, conseqüentemente, a taxa de juros. (CARVALHO; PAUL; NAIDITCH, 2007)

\section{METODOLOGIA}

O questionário aplicado foi elaborado com o objetivo de identificar a percepção das empresas no Novo Mercado da Bovespa, abordando os impactos da Governança Corporativa, tendo como principal foco as empresas listadas no Novo Mercado da Bovespa. Para tanto, elaborou-se um questionário com perguntas especificas sobre os benefícios e obstáculos enfrentados pela Governança e a entrada e manutenção no novo segmento de listagem da Bovespa, o Novo Mercado.

A presente pesquisa tem caráter quantitativo, descritivo e foi realizada por meio de um levantamento, com a aplicação de questionários. Com o objetivo de apresentar os aspectos metodológicos pertinentes à pesquisa, descreveremos a metodologia utilizada. 
Richardson (1999) afirma que, adotando-se uma classificação ampla, podem ser observados dois métodos de pesquisa: quantitativo e qualitativo, que são diferenciados, principalmente, levando-se em consideração a maneira como cada método aborda o problema de pesquisa. Segundo tal classificação, a presente pesquisa pode ser considerada quantitativa, pois procura quantificar os dados e aplica alguma forma de análise estatística (MALHOTRA, 2001). Para Richardson (1999), as técnicas estatísticas aplicadas podem variar desde a aplicação de média simples a complexas análises de regressão. O método qualitativo difere do quantitativo, em princípio, por não empregar instrumental estatístico como base no processo de análise de um problema.

Classifica-se a presente pesquisa como descritiva, já que a mesma tem, como finalidade, "descobrir, com a precisão possível, a freqüência com que um fenômeno ocorre, sua relação e conexão com outros, sua natureza e características." (CERVO; BERVIAN, 1996, p.49). Segundo Gil (1999), são muitos os estudos que podem ser classificados como pesquisa descritiva, que têm como uma de suas características mais significativas a utilização de técnicas padronizadas de coleta de dados.

Assim, de acordo com o que foi exposto, pode-se classificar o presente trabalho como uma pesquisa quantitativa, descritiva, que utilizou o levantamento como fonte de coleta de dados. O processo de coleta de dados, que envolveu a aplicação dos questionários, será descrito detalhadamente no decorrer dos tópicos.

A aplicação do questionário deu-se através do envio do mesmo via e-mail, para o endereço eletrônico do departamento de Relação com Investidores, para 80 companhias listadas no Novo Mercado da Bovespa. Do total de empresas listadas nesse segmento, foi obtido uma taxa de retorno de $17 \%$ dos questionários respondidos. Algumas empresas, porém, justificaram o não envio do questionário por estarem no período de silêncio imposto pela Bovespa e C.V.M.

\section{ANÁLISE DOS RESULTADOS}

O presente artigo teve, como objetivo, identificar a percepção das empresas no Novo Mercado da Bovespa, abordando os impactos da Governança Corporativa, tendo como principal foco as empresas listadas no Novo Mercado da Bovespa. Para tanto, elaborou-se um questionário com perguntas especificas sobre os benefícios e obstáculos enfrentados pela Governança e a entrada e manutenção no novo segmento de listagem da Bovespa, o Novo Mercado.

A aplicação dos questionários ocorreu por meio eletrônico. Optou-se por enviá-los para os e-mails do Departamento de Relações com Investidores (RI) das empresas. Para se chegar ao e-mail do departamento de RI de cada organização, buscou-se a informação no site da BOVESPA. O prazo para resposta dos questionários foi de trinta dias. As empresas que não responderam foram procuradas uma segunda vez, para onde o questionário foi reenviado. O resultado foi uma amostra composta por 14 empresas de um total de 80 questionários enviados.

Após a análise dos questionários respondidos, identificaram-se as seguintes respostas: 
A principal vantagem buscada na abertura de capital na Bolsa de Valores é a captação de recursos financeiros como forma de financiamento da empresa, sem aumentar seu endividamento. Em seguida, é considerada uma excelente forma de arranjo societário e desenvolvimento da imagem da empresa, tendo em vista a vitrine que é o mercado de capitais. Mas, atualmente, também é considerada uma estratégia de saída dos fundos de private equity que desejam adquirir controle de companhias com potencial de lucros.

Verificou-se que as empresas são motivadas a aderir a práticas diferenciadas de governança corporativa, fundamentalmente, pela expectativa de valorização das ações, pelo aumento do nível de informações prestadas e, também, pela maior liquidez das ações. Identificou-se ainda que a adoção dessas práticas dá-se em razão de exigências dos stakeholders ${ }^{7}$ e pelo setor de atuação.

Como principais resultados positivos percebidos pelas empresas que adotam a governança corporativa estão, primeiramente, o fato de as ações obterem uma valorização diferenciada pelo aumento das informações prestadas ao mercado. O fator secundário dá-se quanto à redução do custo de capital, seguida, ainda, da maior liquidez das ações, sendo todas conferidas à maior profissionalização da gestão da companhia.

Entre as principais dificuldades na implantação e manutenção da Governança Corporativa, foram citados fatores com alto grau de entraves, a conscientização dos colaboradores internos quanto a seu envolvimento no processo de implantação do novo sistema. Outros fatores de dificuldade são os excessos de exigências dos órgãos reguladores e o tempo para cumprimento dessas exigências que inserem barreiras na implantação e manutenção do sistema.

Quanto às maiores dificuldades compreendidas no Novo Mercado, constatou-se que a melhoria na prestação das informações por seu alto custo financeiro das publicações legais é um fator de entrave considerável. Segue-se que a exigência de dispersão acionária traz grande obstáculo para as empresas, e a exigência de que a companhia deve possuir $100 \%$ das ações ordinárias envolve dificuldades que devem ser enfrentadas para que essas estejam aptas à listagem do Novo Mercado.

Após a entrada das companhias no Novo Mercado, são perceptíveis três principais fatores de benefícios para as empresas, a valorização das ações na Bolsa, o crescimento do interesse de capital estrangeiro nas ações da empresa e uma maior visibilidade da companhia na mídia e no mercado atuante. Esses fatores são relativos à adoção de práticas diferenciadas de Governança Corporativa e percebe-se que essas concedem vantagens às empresas.

A concessão de igualdade de direitos aos minoritários confere à companhia o principal motivo do aumento da confiança dos acionistas e do mercado em geral. Constatou-se ainda que possuir um Conselho de Administração e Conselho Fiscal, e a oferta de $100 \%$ das ações ordinárias com direito a voto apresentam alto grau de influência no aumento da confiança dos acionistas, fazendo com que estes estejam dispostos a investir nas empresas que apresentam tais características e tenham boas divulgações de informações.

$7 \quad$ Stakeholder ou, em Português, parte interessada ou interveniente, refere-se a todos os envolvidos em um processo, por exemplo, clientes, colaboradores, investidores, fornecedores, comunidade, etc.(CVM, 2007) 
Foi identificado, também, através da aplicação do questionário, que as principais funções do departamento de Relações com Investidores estão relacionadas à prestação de informações ao Mercado; atuando também como porta-voz do Conselho de administração em comunicações sobre estratégias da companhia, assim como a prestação de informações de negociações dos valores mobiliários. Esse departamento é essencial dentro da companhia, pois contempla funções de relacionamento constante com os investidores, e possuir um departamento competente e prestativo significa uma vantagem competitiva.

O quadro abaixo foi elaborado para apresentar uma síntese dos resultados obtidos com a presente pesquisa. São apresentadas as três questões listadas em ordem de importância 1, 2, e 3 com referência percentual à quantidade de empresas que responderam respectivamente à questão.

Tabela 2: Resultados do questionário. (Continua)

\begin{tabular}{|c|c|}
\hline Questão de Investigação & Resultados Obtidos \\
\hline $\begin{array}{l}\text { 1) Qual a principal vantagem que motivou a empresa à } \\
\text { abertura de capital }\end{array}$ & $\begin{array}{l}1 \text { - }(50 \%) \text { Captação de recursos financeiros } \\
2 \text { - }(21 \%) \text { Desenvolver a imagem institucional } \\
3 \text { - (14\%) Arranjo societário }\end{array}$ \\
\hline $\begin{array}{l}\text { 2) O que motivou a empresa a implantar os níveis } \\
\text { diferenciados de governança corporativa? }\end{array}$ & $\begin{array}{l}1 \text { - }(21 \%) \text { Expectativa de valorização das ações } \\
2 \text { - }(36 \%) \text { Aumentar a qualidade das informações } \\
\text { prestadas } \\
\text { 3- }(21 \%) \text { Expectativa de maior liquidez das ações }\end{array}$ \\
\hline $\begin{array}{l}\text { 3) Quais os resultados positivos da Governança } \\
\text { Corporativa? }\end{array}$ & $\begin{array}{l}1 \text { - }(29 \%) \text { Valorização das ações } \\
2 \text { - }(36 \%) \text { Redução do custo de capital } \\
3 \text { - (36\%) Maior liquidez das ações }\end{array}$ \\
\hline $\begin{array}{l}\text { 4) Quais as dificuldades na implantação e manutenção } \\
\text { da governança corporativa? }\end{array}$ & $\begin{array}{l}1-(14 \%) \text { Conscientização dos colaboradores } \\
2-(21 \%) \text { Tempo para cumprimento das exigências } \\
3-(21 \%) \text { Excesso de exigências dos órgãos } \\
\text { reguladores }\end{array}$ \\
\hline $\begin{array}{l}\text { 5) Quais das exigências do Novo Mercado possuem } \\
\text { maiores entraves para serem cumpridos. }\end{array}$ & $\begin{array}{l}1 \text { - }(29 \%) \text { Melhoria na prestação de informações. } \\
2 \text { - }(36 \%) \text { Dispersão acionária } \\
3 \text { - (14\%) Possuir } 100 \% \text { das ações ordinárias }\end{array}$ \\
\hline $\begin{array}{l}\text { 6) Após a abertura de capital no Novo Mercado quais as } \\
\text { vantagens percebidas pela Companhia? }\end{array}$ & $\begin{array}{l}1 \text { - }(21 \%) \text { Valorização das ações na bolsa } \\
2 \text { - }(29 \%) \text { Crescimento do interesse de capital } \\
\text { estrangeiro nas ações da empresa } \\
3 \text { - }(21 \%) \text { Maior visibilidade da companhia na mídia } \\
\text { e no mercado atuante }\end{array}$ \\
\hline
\end{tabular}


Tabela 2: Resultados do questionário. (Conclusão)

\begin{tabular}{l|l}
\hline & $1-(29 \%)$ Conceder igualdade de condições aos \\
7) Qual das exigências do N.M. cumpridas pela & minoritários \\
Companhia tem representado maior influência no & $-(14 \%)$ Possuir Conselho de Administração e \\
aumento da confiança dos acionistas? & Conselho Fiscal \\
& $3-(29 \%)$ Possuir $100 \%$ das ações ordinárias com \\
& direito a voto \\
\hline & $1-(57 \%)$ Prestação de informações ao Mercado \\
8) Principais atribuições do departamento de Relações & $2-(21 \%)$ Porta-voz do Conselho de Administração \\
com Investidores. & em comunicações estratégicas \\
& $3-(36 \%)$ Prestação de informações de negociações \\
& dos valores mobiliários \\
\hline
\end{tabular}

\section{CONCLUSÃO}

Com base na importância da Governança Corporativa no contexto atual do mercado de capitais e na economia brasileira, o presente artigo teve como objetivo identificar a percepção das empresas no Novo Mercado da Bovespa, abordando os impactos da Governança Corporativa, tendo como principal foco as empresas listadas no Novo Mercado da Bovespa. Para tanto, elaborou-se um questionário com perguntas especificas sobre os benefícios e obstáculos enfrentados pela Governança e a entrada e manutenção no novo segmento de listagem da Bovespa, o Novo Mercado.

Através da análise dos resultados dos questionários respondidos, concluiu-se que a abertura de capital da companhia é decidida por seus controladores como solução de perenidade e sustentabilidade, independentemente da presença desses na empresa no futuro. A governança colabora com diversos fatores para a ampliação do nível de profissionalização e aprimoramento dos modelos de gestão. Benefícios, como a criação de um Conselho de Administração nas empresas trazem a visão de conselheiros independentes de diversas áreas de negócios, contribuindo para a melhoria da empresa como um todo. A cooperação da governança vai além, auxiliando empresas com raízes familiares ou não na profissionalização da gestão estratégica, aumentando a disciplina na gestão e alinhando todas as áreas da companhia, impetrando o aperfeiçoamento dos modelos de gestão, de planejamento, orçamento e prestação de contas que passam a ser trimestrais.

A transição cultural da empresa com capital fechado para aberto traz o envolvimento dos "stakeholders" mesmo que conseguido com dificuldades contribui para o reforço da imagem institucional da empresa para reportar-se ao mercado.

Verifica-se que, no contexto atual, a Governança Corporativa atribui mais benefícios do que apresenta dificuldades e que as principais expectativas das empresas, antes da implantação das práticas de gestão, são cumpridas após a utilização do novo sistema.

Constatou-se também que as práticas de Governança contribuem para o aumento de 
confiança dos acionistas e mercado em geral, por aumentar o volume de informações apresentadas ao mercado.

A limitação do presente trabalho encontra-se na quantidade de empresas que compuseram a amostra, ficando como principal sugestão para trabalhos futuros, uma forma de aplicação de questionários mais abrangente.

Ressalta-se, ainda, que se torna interessante ser feito posteriormente um estudo com maior profundidade sobre o tema dado e sua importância na economia brasileira.

\section{REFERÊNCIAS}

BARBOSA, M. Fique sócio da Petrobrás. Exame Você S/A. São Paulo, n.5, ed.95, p.48-56, maio/2006.

BOVESPA. Empresas. Sumário. Governança corporativa. São Paulo, mar.2007. Disponível em: http://www.bovespa.com.br/Principal.asp. Acesso em: 03 ago.2007.

BOVESPA. Empresas. Dicionário de Finanças. São Paulo, mar.2007. Disponível em: http:// www.bovespa.com.br/Principal.asp. Acesso em: 03 ago.2007.

CARVALHO, D.; PAUL, G.; NAIDITCH, S. A bolsa em 50 mil pontos. Revista Exame. São Paulo, n.7, ed.891, p.20-28, abr. 2007.

CERVO, A.L.; BERVIAN, P.A. Metodologia científica. 4.ed. São Paulo: Makron Books, 1996.

CICOGNA, M.P.V; TONETO, R.T; VALLE, M.R. O impacto da adesão a padrões mais elevados de governança sobre o financiamento empresarial. R.Adm, São Paulo, v.42 n.1, p.52-63, jan./ fev./mar.2007.

GIL, A.C. Métodos e técnicas de pesquisa social. 5.ed. São Paulo: Atlas, 1999.

IBGC - Instituto Brasileiro de Governança Corporativa. Uma Publicação de Governança corporativa. São Paulo, ago.2007. Disponível em: http://www.ibgc.org.br/ibConteudo. asp?IDArea=2. Acesso 08.Ago.2007.

LAMEIRA, V.J; JUNIOR, W.L.N; SOARES, T.D.L.V.A.M. Governança corporativa: impacto no valor das companhias abertas brasileiras. R.Adm, São Paulo, v.42, n.1, p.64-73, jan./fev./ mar.2007.

MALHOTRA, N.K. Pesquisa de marketing: uma orientação aplicada. 3.ed. Porto Alegre: Bookman, 2001.

PINHEIRO, J.L. Mercado de capitais: fundamentos e técnicas. São Paulo: Atlas, 2001. 
RICHARDSON, R.J. Pesquisa social: métodos e técnicas. 3.ed. São Paulo: Atlas, 1999.

SANTOS, C. M. dos. Levantamento dos fatores determinantes da estrutura de capital das empresas brasileiras. Ribeirão Preto: Faculdade de Economia, Administração e Contabilidade de Ribeirão Preto da Universidade de São Paulo.

TOMAZ, L.M. Governança corporativa, desempenho e valor das empresas: caso grupo Ultrapar. Ituverava: FE/FFCL, 2006. Trabalho de Conclusão de curso (Graduação em Administração - Gestão de negócios). Faculdade de Filosofia Ciência e Letras. Fundação Educacional de Ituverava.

\section{ANEXOS}

\section{Questionário de Trabalho de Conclusão do Curso Administração de Empresas Tema: Governança Corporativa}

Faculdade de Filosofia Ciências e Letras de Ituverava

Solicitamos que ao responder o questionário liste os itens por ordem de importância com números. Sendo 1 para o mais importante e até 8, conforme a quantidade de respostas, para o de menor importância.

01 - Qual a principal vantagem que motivou a empresa à abertura de capital?

( ) Captação de recursos financeiros

( ) Arranjo societário

( ) Desenvolver a imagem institucional

( ) Outros Especifique:

02 - O que motivou a empresa a implantar os níveis diferenciados de governança corporativa?

( ) Expectativa de valorização das ações

( ) Aumentar a qualidade das informações prestadas

( ) Dispersão acionária

( ) Expectativa de maior liquidez das ações

( ) Atender exigências dos stakeholders

( ) Necessidade gerada pelo setor (os principais concorrentes já praticam)

( ) Outros Especifique:

03 - Quais os resultados positivos da Governança Corporativa?

( ) Maior liquidez

( ) Valorização das ações

Nucleus, v. 5. n. 1 , abr. 2008 
( ) Dispersão acionária

( ) Redução do custo capital

( ) Profissionalização da gestão

( ) Melhoria das relações comerciais ( clientes e fornecedores )

( ) Outros Especifique:

04 - Quais as dificuldades na implantação e manutenção da governança corporativa?

( ) Perda de confidencialidade

( ) Conscientização dos colaboradores

( ) Custos da implantação e manutenção

( ) Dificuldade de encontrar profissionais com experiência

( ) Tempo para cumprimento das exigências

( ) Excesso de exigências pelos órgãos reguladores

( ) Outros Especifique:

05 - Quais das exigências do Novo Mercado possuem maiores entraves para serem cumpridos.

( ) Melhoria na prestação de informações.

( ) Dispersão acionária

( ) Possuir $100 \%$ das ações ordinárias

( ) Outros Especifique:

06 - Após a abertura de capital no Novo Mercado quais as vantagens percebidas pela Companhia?

( ) Aumento no índice de liquidez das ações da Companhia

( ) Valorização das ações na Bolsa

( ) Crescimento do interesse de capital estrangeiro nas ações da empresa

( ) Maior visibilidade da companhia na mídia e no mercado atuante

( ) Melhoria nos processos de gestão da empresa

( ) Redução do custo de capital

( ) Outros Especifique:

07 - Qual das exigências do N.M. cumpridas pela Companhia tem representado maior influência no aumento da confiança dos acionistas?

( ) Divulgação de informações financeiras periódicas em padrões internacionais 
( ) Assembléias e reuniões para apresentação de resultados

( ) Mecanismos de dispersão acionária

( ) Possuir Conselho de Administração e Conselho Fiscal

( ) Conceder igualdade de condições aos minoritários (Tag Along)

( ) Adesão à Câmara de Arbitragem

( ) Inspeção por Auditoria independente

( ) Possuir 100\% das ações ordinárias com direito a voto

( ) Outros Especifique:

08 - Sabe-se que o Departamento de Relações com Investidores exerce função importante nas Companhias com capital aberto. Liste em ordem de importância as principais atribuições desse departamento.

( ) Desenvolvimento da imagem institucional da Companhia.

( ) Prestação de informações de negociações dos valores mobiliários

( ) Realização de assembléias ordinárias

( ) Prestação de informações ao Mercado

( ) Porta-voz do Conselho de administração em comunicações sobre estratégias da companhia

( ) Outros Especifique: 